Departamento de Inðústria, Inspeção e Conservação de Produtos Alimentícios de Origem Animal Prof. contratado - Paschoal Mucciolo

\title{
A PROVA DA PRECIPITAÇÃO EM INSPEÇÃO DE CARNES - AÇÃO DO ÁCIDO ASCÓRBICO NA PREPARAÇÃO DE SÔROS DE ALTO TÍTULO \\ POR
}

\section{Paschoal Mucciolo}

O inspetor de carnes chamado a estabelecer diferenças entre carcassas ou órgãos dos vários animais de açougue terá tarefa relativamente fácil, reportando-se aos caracteres anatômicos e físico-organolépticos peculiares às carnes das espécies em exame. $\mathrm{O}$ mesmo não acontece, entretanto, quando a intervenção do técnico é solicitada para discernir da proveniência de pequenos fragmentos de carnes produtos embutidos - casos em que os caracteres citados nenhuma elucidação trazem, cedendo lugar às mais variadas provas de laboratório.

As substituições fraudulentas dizem respeito à carne fresca on às carnes por qualquer forma manipuladas, isto é, aos diversos produtos de salsicharia cuja composição é frequentemente alterada, posto que, preparações dessa natureza se prestam perfeitamente a ludibriar não só a vigilância sanitária, como tambem a boa fé do consumidor, adquirindo carnes de espécie não indicada no momento da compra.

De tôdas as fraudes dêsse tipo é a substituição da carne de bovino pela de equino a mais frequente e a que, mesmo nos países onde a hipofagia entrou para o uso público, tem merecido especial atenção por parte das autoridades competentes, no sentido de coibir abusos de fabricantes inescrupulosos, como o afirma PIETTRE (1).

E' interessante notar que, embora presentemente não se faça, entre nós, uso de carne dessa espécie doméstica, nosso Regulamento (2) cogite, em sua secção II do capítulo VII, da matança de equídeos e é muito prudente e explícito, com o fim de evitar equívocos, quando torna obrigatório, nos produtos elaborados com carnes dessa espécie, a apresentação de marcas e legendas bem visíveis declarando a qualidade da carne empregada.

Em se tratando de carne fragmentada e já industrializada a distinção de espécie só poderá ser feita com vistas aos caracteres químicos das carnes, físico-químicos das gorduras ou pelo teste biológico.

Análisemos rápidamente essas diversas provas quanto à sua eficiência e facilidade de execução, tecendo crítica sumária das mesmas. 
Os métodos químicos mais usados para revelar carne de cavalo são: a dosagem do glicogênio e os índices de iodo e de saponificação das gorduras; êstes dois últimos índices tambem se prestam para reconhecimento de carnes de outras espécies.

Entre as provas de uso corrente nos laboratórios encarregados da fiscalização e policiamento dos produtos alimentícios de origem animal ainda se enquadram: os pontos de fusão e solidificação e o índice de refração das gorduras.

Sendo necessário revelar a substituição fraudulenta da carne de bovino pela de equino, quer se trate de carne fresca ou de embutidos, o método de Mayrhofer-Polenske, aconselhado nestes casos pelas obras clássicas de Bertolini (3) e Piettre (1), é de valor relativo e como diz textualmente êste último autor "os resultados obtidos são sobretudo teóricos». De fato, a carne de equino possue alto teor em glicogênio comparativamente às carnes dos outros animais de açougue, variando entretanto essa quantidade com o estado de nutrição e de fadiga do animal e com os grupos musculares em exame. Além disso, carnes fetais e as de outras espécies domésticas podem conter apreciável quantidade de glicogênio como acontece com as de vitelos caquéticos, incluindo EdelmanN (4) nêste grupo, as carnes de cães e gatos. Em se tratando de verificar a fraude em embutidos as dificuldades aumentam consideravelmente porque como fazem notar Gauthier e Bujard (Cit. de Bertolini), não só o glicogênio, por ação de enzimas especiais, se transforma em glicose, como tambem desaparece sob influência da salgação e defumação.

A dosagem do glicogênio, apresentando algum valor para diferençar carnes frescas, não pode servir, pois, de base suficientemente sólida para a inspeção de embutidos pelas razões já enumeradas, sem considerarmos que, sendo empregado o amido como aglutinante das misturas de alguns dêsses produtos, os dois hidratos de carbono ficam igualmente insolúveis na potassa alcoólica e sua separação exige manipulações longas e demoradas.

Os outros métodos citados, referindo-se aos caracteres físicoquímicos das gorduras, uns exigindo técnica e laboratórios especializados, outros implicando em aparelhagem custosa, como é o caso do índice de refração, não se prestam a estabelecer diferença nítida entre as gorduras das várias espécies. Basta lembrar que, sendo a gordura de cavalo diferente das gorduras de bovino, caprino e ovino por conter em sua composição maior quantidade de gliceridos do ácido oleico, linólico e palmítico enquanto estas últimas contêm normalmente grande proporção de gliceridos de ácido esteárico, e daí ser fácil a identificação, o mesmo não se dá com a gordura de suíno, em cuja 
composição os gliceridos do ácido linólico têm a primasia. Dêsse fato se depreende que nenhuma distinção se poderá fazer entre produtos preparados com carnes de cavalo e de suíno, unicamente baseada nos caracteres da composição química da gordura. A estas dificuldades se ajunte que nem sempre o material sujeito a exame é discretamente rico em gordura, pois sobretudo a fraude da troca de carne de bovino pela de equino tem por objetivo o aproveitamento das carnes de animais esgotados ou doentes e, por êsses motivos, retirados de sua habitual função zootécnica.

E' ao teste biológico, pondo em evidência determinados caracteres das albuminas, traindo dêsse modo suas origens, que cabe incontestável valor na investigação das fraudes por substituição, não só nas carnes frescas como nos produtos de carne picada.

Ao tratar do assunto, incluem farreras e Sanz Egaña (5) entre os métodos biológicos utilizados em inspeção, a precipitação, a anafilaxia e a fixação do complemento a que podemos ajuntar o método baseado sôbre a pesquisa do antígeno Forssmann, proposto por E. Césari (Cit. de BertolinI) para a repressão de fraudes nos produtos cárneos submetidos à cocção. Enquanto a anafilaxia, a fixação do complemento e a pesquisa do antígeno Forssmann, não tiveram até agora larga aplicação prática, deixando de se alinhar entre as provas de uso corrente em inspeção, servindo as duas primeiras apenas como testes suplementares de contrôle, no dizer de Ostertag (6), a precipitação mostrou-se um meio preciso e seguro para a diferenciação das carnes, pelo que sua importância é unânimemente reconhecida pelos autores clássicos.

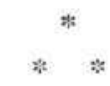

Feitas estas considerações sôbre os vários métodos empregados para caraterizar carnes dos diversos animais sob várias formas utilizadas na alimentação do homem, passaremos a nos ocupar do teste das precipitinas ou dos sôros precipitantes, único objetivo do presente trabalho. $\left(^{*}\right)$

Não é nosso propósito referir aqui a natureza, mecanismo e técnica da reação, mas apenas diremos que o método repousa na possibilidade de obter sôros, precipitando "in vitro» a albumina homologa áquela que serviu como antígeno, sendo o coelho o animal de escolha para a imunização.

Os antígenos têm todos os caracteres de especificidade e são, no estado atual de nossos conhecimentos, exclusivamente representa-

(*) Usámos a técnica descrita por BERTOLINI e CAZZELLA (3) pgs. 178-184. 
dos pelas substâncias proteicas, conforme as modernas concepções da teoria físico-química da imunidade. Essa especificidade não é, entretanto, atributo de espécie, como faziam entrever as antigas explicações dos fenômenos imunitários, mas obedecem unicamente aos caracteres químicos do antígeno. Ora, oferecendo as proteinas uma variedade considerável de composição, pelo infinito número de combinações possíveis dos amino-ácidos seus constituintes, está claro que a especificidade se mostrará tambem extremamente variável.

Por essa razão podemos observar uma espécie animal oferecendo muitos antígenos, enquanto que um mesmo antígeno pode fazer parte de espécies diferentes, como relata Fonseca Ribeiro (7). No primeiro caso, tomando emprestado os exemplos do autor citado, encontramos no ovo de galinha cinco antígenos individualizados, no sôro de cavalo três proteinas de caracteres imunológicos distintos enquanto a caseína de um animal é facilmente diferençada dos outros constituintes proteicos do leite e do sôro. Por outro lado, não se podem diferenciar as albuminas cristalizadas dos ovos de galinha e de pata, as caseínas dos animais de diferentes espécies ou as proteinas do cristalino, que oferecem as mesmas caraterísticas para tôdas as espécies.

As manifestações de especificidade que acabámos de ver nos exemplos citados, antes só evidenciáveis pela delicadeza das reações de imunidade, à luz dos modernos conhecimentos, já têm expressão química definida e daí ser a especificidade mais ligada à constituição química do antígeno que à origem biológica do mesmo.

Fato interessante é o de certos radicais químicos que introduzidos na molécula proteica the conferem caracteres antigenéticos especificamente novos, a ponto de se conseguirem anticorpos pela imunização de um animal com suas próprias proteinas modificadas. Entre êsses radicais capazes de se enxertarem às proteinas, chamados haptenas por Landsteiner (cit. Fonseca Ribeiro), temos: hidratos de carbono, formol, ácido nítrico, iodo, ácido metanílico e outros, cuja especificidade é de tal modo evidente a ponto de tornar possível discriminar compostos químicos isômeros. Caberia assim a êsses radicais todo o valor de especificidade quando ligados a uma proteina caracteristicamente dotada de poder antigenético.

As reações de grupo observadas na prática entre espécies afins explicam-se, pois, pela presença de uma proteina comum às mesmas ou talvez de um mesmo radical químico emprestando-lhes características semelhantes.

Acresce notar que a especificidade dos sôros precipitantes é tanto mais evidente quanto mais alto fôr seu título. Isto quer dizer que, obtendo sôros muito sensíveis, capazes de precipitar albumina 
homóloga extremamente diluida, a reação será então muito mais intensa e rápida, fazendo desaparecer assim as confusões ou interpretações errôneas quando se põe em prática o teste biológico. Nessas condições, o método ganhará toda a eficiência e precisão de extrita especificidade.

\section{AÇÃO DO ÁCIDO ASCÓRBICO ESTIMULANDO A PRODUÇÃO DE PRECIPITINAS}

Foi nosso intuito ao iniciarmos o presente trabalho, a obtenção de sôros precipitantes de título elevado, contribuindo assim a tornar mais eficiente o teste biológico, acreditando que com isto possa o mesmo vir em auxílio do técnico encarregado de se pronunciar com segurança sôbre as substituições fraudulentas a que estão sujeitos os produtos de carne.

JUSATz (8) submetendo coelhos, injetados com sôro normal de cavalo, a um regime alimentar pobre em vitaminas verificou que o poder precipitante e bactericida do sôro dêsses animais era relativamente baixo e quasi nulo quando a alimentação era autoclavada a $120^{\circ}$. Procurando precisar o fator determinante do baixo índice bactericida do sôro e que tanta influência exercia na produção de anticorpos específicos, êste A. introduziu, parceladamente, no regime alimentar dêsses animais de experiência, as vitaminas $A, B, C$ e $D$. Dêsse modo conseguiu demonstrar que, a adição de vitamina $A$, em doses progressivas, não faz reaparecer o poder bactericida do sôro nos animais avitaminados. A administração de vitamina $D$, em doses fracas, não influencía a produção de anticorpos que passa a ser relativamente escassa quando os animais em carência recebem doses fortes dessa vitamina. Quanto à vitamina $B$, poude JusaTz constatar que a adição da mesma (dose de 15 grs. de levedo) à nutrição não melhora a produção de anticorpos. Empregando a vitamina $C$ observou que, embora não exercendo influência quando adicionada à nutrição, o ácido ascórbico aumenta de duas vêzes o poder bactericida do sôro e cinco vêzes o título das precipitinas específicas, sendo injetado por via venosa. MADISON e MANWARING (9) confirmaram mais tarde os trabalhos de Jusatz estabelecendo que a adição de ácido ascórbico ao sôro de cavalo na dose de $100 \mathrm{mg}$. em $0,5 \mathrm{cc}$. de água destilada $(20 \%)$ e injetado por via venosa em coelhos, determina um título mais elevado do sôro precipitante e uma aceleração da reação de precipitação. Puderam ainda observar que as doses maciças de ácido ascórbico impedem a produção de anticorpos e, nêste fato, certamente, reside o insucesso obtido por alguns experimentadores, porquanto a dose ótima de vitamina varia de $37,5 \mathrm{mg}$. (MAdison e col.) 
a $66 \mathrm{mg}$. (Jusatz). E' de se notar que, enquanto Madison e col. empregaram a vitamina juntamente com o antígeno em injeções repetidas, JUSATZ recomenda o uso da mesma imediatamente antes da injeção do antígeno.

De posse dêsses resultados, iniciámos nossas observações com uma série de 5 coelhos (quadro n. ${ }^{\circ}$ 1) dos quais um veio a morrer antes mesmo de ser sangrado:

QUADRO N.o 1

Ação do ácido ascórbico na produção de precipitinas

\begin{tabular}{r|c|c|c|c}
\hline $\begin{array}{c}\text { Dias de } \\
\text { inoculação }\end{array}$ & $\begin{array}{c}\text { Sôro normal } \\
\text { de cavalo }\end{array}$ & $\begin{array}{c}\text { Solucão de } \\
\text { aćido } \\
\text { ascórbico }\end{array}$ & Observações & $\begin{array}{c}\text { Titulo preciplt. } \\
\text { (média) }\end{array}$ \\
\hline \hline 1.0 & $1 \mathrm{cc}$. & - & - & - \\
6.0 & $1 \mathrm{cc}$. & - & - & - \\
12.0 & $1 \mathrm{cc}$. & - & - & - \\
18.0 & $1 \mathrm{cc}$. & - & - & - \\
26.0 & - & $1 \mathrm{cc}$. & Sangria & $1: 500$ \\
29.0 & - & - & Sangria & $1: 1.000$ \\
\hline
\end{tabular}

A imunização feita com sôro normal de cavalo em quatro injeções de 1 cc., com intervalo de seis dias, resultou um sôro-coelho anticavalo de título igual a 1:500 em média. No mesmo dia dessa primeira sangria injetámos, em todos os animais de experiência, 1 cc. de uma solução de ácido ascórbico $\left(^{*}\right)$ em água destilada a $8 \%$ ou seja dose de $0,080 \mathrm{mg}$. Passados tres dias procedemos a uma segunda sangria, revelando então o sôro obtido um título precipitante de 1:1.000.

Feitas estas experiências preliminares, usando sempre sôro normal de cavalo como antígeno, iniciámos a imunização de mais um grupo de quatro animais (coelhos), como indica o quadro n. 2 .

À primeira sangria seguiu-se a injeção da solução de ácido ascórbico nas mesmas condições da experiencia anterior, variando apenas o título da solução de vitamina que, no presente caso, foi de $9 \%$ ou seja 0,090 mg. por animal.

Dos resultados por nós obtidos, confirmando os trabalhos de Jusatz, Madison e col., quanto à ação estimulante da vitamina $C$, sôbre a produção de anticorpos precipitantes quando administrada por

(*) Procedência: J. D. RIEDEL - E. DE HAËN A. C. Berlin. 
QUADRO N.० 2

Ação do ácido ascórbico na produção de precipitinas

\begin{tabular}{r|c|c|c|c}
\hline $\begin{array}{c}\text { Dias de } \\
\text { inoculaçấo }\end{array}$ & $\begin{array}{c}\text { Sôro normal } \\
\text { de cavalo }\end{array}$ & $\begin{array}{c}\text { Solução } \\
\text { de ácido } \\
\text { ascórbico }\end{array}$ & Observações & $\begin{array}{c}\text { Titulo precipit. } \\
\text { (média) }\end{array}$ \\
\hline \hline $1 . \circ$ & $1 \mathrm{cc}$ & - & - & - \\
$8.0^{\circ}$ & $2 \mathrm{cc}$. & - & - & - \\
18.0 & $2,5 \mathrm{cc}$. & - & - & - \\
27.0 & $3 \mathrm{cc}$. & - & - & - \\
39.0 & - & $1 \mathrm{cc}$. & Sangria & $1: 2.000$ \\
52.0 & - & - & Sangria & $1: 32.000$ \\
54.0 & $1 \mathrm{cc}$. & - & - & - \\
56.0 & - & - & Sangria & não houve \\
57.0 & - & $1 \mathrm{cc}$. & - & - \\
59.0 & - & - & Sangria & $1: 2.000$ \\
67.0 & - & - & Sangria & $1: 1.000$ \\
\hline
\end{tabular}

via venosa, ainda podemos concluir não serem necessárias doses repetidas de ácido ascórbico quer no início da imunização, quer injetadas simultâneamente com o antígeno. De fato, ainda utilizando os mesmos animais da experiência anterior, procedemos a mais uma observação, quadro n.o 3 ,

QUADRO N.0 3

Ação do ácido ascórbico na produção de precipitinas

\begin{tabular}{r|c|c|c|c}
\hline $\begin{array}{c}\text { Dias de } \\
\text { inoculação }\end{array}$ & $\begin{array}{c}\text { Sôro normal } \\
\text { de cavalo }\end{array}$ & $\begin{array}{c}\text { Soluçâo de } \\
\text { ácído } \\
\text { ascórbico }\end{array}$ & Observações & $\begin{array}{c}\text { Titulo precipit. } \\
\text { (média) }\end{array}$ \\
\hline 1.0 & $1 \mathrm{cc}$. & - & Sangria & Não houve \\
7.0 & $1,5 \mathrm{cc}$. & - & - & - \\
14.0 & $2 \mathrm{cc}$. & - & - & - \\
21.0 & $2,5 \mathrm{cc}$. & - & - & - \\
33.0 & - & $1 \mathrm{cc}$. & Sangria & $1: 4.000$ \\
38.0 & - & - & Sangria & $1: 8.000$ \\
\hline
\end{tabular}

iniciando a reimunização, tendo o cuidado de verificar antes a ausência, em seu sôro, de qualquer poder precipitante, o que foi feito depois de trinta dias de terminada a primeira imunização. Empregámos também nêste caso uma única injeção da solução de ácido ascórbico a $10 \%$ (dose de $0,100 \mathrm{mg}$.), conseguindo do mesmo modo ativar a produção de anticorpos específicos, fato que se revelou pelo título precipitante mais elevado conferido ao sôro. 
Sendo, portanto, relativamente fácil conseguir sôros cujos títulos precipitantes alcancem cifras muito elevadas prescindindo de muitas inoculações de antígeno, pelo simples emprego de uma única injeção de ácido ascórbico no fim da imunização, o teste biológico adquire sua máxima eficiência na caracterização das carnes dos vários animais de açougue. De técnica fácil, não exigindo aparelhagem de espécie alguma, pode o teste biológico ser realizado não só nos laboratórios especializados como tambem nas inspeções anexas aos estabelecimentos que elaboram produtos de salsicharia.

\section{INFLUENCIA DO ÃCIDO ASCORBICO NA PRODUÇÃO DE AGLUTININAS ESPECIFICAS}

Tendo obtido resultados tão satisfatórios com o emprego da vitamina $C$ em animais produtores de sôros precipitantes, quisemos extender nossas observações, procurando saber qual o comportamento da mesma na produção de aglutininas.

MADISON e colaboradores (10) injetaram doses maciças de ácido ascórbico em coelhos submetidos à imunização com glóbulos de carneiro e bactérias de várias espécies vivas ou mortas, verificando que o teor em aglutininas dos sôros dêsses animais decrescia grandemente, na razão de $60 \%$. Estudando o mesmo assunto, Montalti e PAsseRINI (11) puderam observar que a produção de aglutininas antitíficas era prejudicada quando os animais produtores de sôro eram submetidos a dietas deficientes ou enriquecidas com ácido ascórbico. Por outro lado, Cattaneo e Morellini (12) verificaram um aumento da produção de aglutininas anticoli quando, aos animais em imunização, eram administradas substâncias redutoras do tipo do hiposulfito de sódio, ácido ascórbico e adrenalina, substâncias estas empregadas pelos autores citados em suas experiências.

Em vista de resultados tão discordantes obtidos pelos experimentadores que se ocuparam do assunto, procurámos modificar a técnica por êles utilizada, não só empregando cavalos como animais de experiência, como tambem usando doses mais fracas da vitamina em questão por via venosa.

Os animais por nós utilizados foram vinte cavalos submetidos à imunização diftérica $\left({ }^{*}\right)$. Dêsses animais dez serviram de testemunhos, enquanto os restantes foram divididos em dois grupos.

Os animais do primeiro grupo, em número de quatro, receberam, em plena imunização, três injeções de ácido ascórbico na dose de 5 grs. por via venosa, exceção feita para o animal de n. ${ }^{\circ} 73$

(") Consignamos aqui os nossos sinceros agradecimentos aos dírigentes do Instituto Pinheiros que tâo gentilinente nos facultaram os recursos para essa experiência. 
que apenas foi injetado uma vez (quadro n.o 4). Essas injeções de vitamina foram aplicadas com intervalo de sete dias não conseguindo influenciar, de modo evidente, o poder antitóxico do sôro, diminuindo-o mesmo em alguns casos.

QUADRO N.0 4

Ação do ácido ascórbico na produção de aglutininas

\begin{tabular}{|c|c|c|c|c|c|}
\hline Data & & $\underset{n 0^{\circ} 69}{\text { Animal }}$ & $\begin{array}{l}\text { Animal } \\
\text { n. } 0^{\circ} 70\end{array}$ & $\begin{array}{c}\text { Animal } \\
n 0^{\circ} 73\end{array}$ & $\begin{array}{c}\text { Animal } \\
\text { n. } 0^{\circ} 75\end{array}$ \\
\hline $18 / 3 / 40$ & $\begin{array}{l}\text { Toxina } \\
\text { Floculação : : : : : } \\
\text { Peso }\end{array}$ & $\begin{array}{r}200 \\
0,05 \\
348\end{array}$ & $\begin{array}{l}200 \\
0,1 \\
320\end{array}$ & $\begin{array}{r}200 \\
0,03 \\
320 \\
\end{array}$ & $\begin{array}{r}200 \\
0,05 \\
325 \\
\end{array}$ \\
\hline $25 / 3 / 40$ & $\begin{array}{l}\text { Toxina } \\
\text { Floculaçấo : : : : : } \\
\text { Peso }\end{array}$ & $\begin{array}{r}250 \\
0,04 \\
340 \\
\end{array}$ & $\begin{array}{r}250 \\
0,08 \\
315 \\
\end{array}$ & $\begin{array}{r}250 \\
0,02 \\
310 \\
\end{array}$ & $\begin{array}{r}250 \\
0,04 \\
325 \\
\end{array}$ \\
\hline $1 / 4 / 40$ & $\begin{array}{l}\text { Toxina ascórbico : : } \\
\text { Acido asco : } \\
\text { Floculação : : } \\
\text { Peso : } \\
\text { Observações : : }\end{array}$ & $\begin{array}{l}300 \\
5,0 \text { grs. } \\
0,04 \\
340 \\
-\end{array}$ & $\begin{array}{l}300 \\
5,0 \text { grs. } \\
0,08 \\
310 \\
- \\
\end{array}$ & $\begin{array}{c}5, \overline{0} \text { grs. } \\
0,03 \\
\text { Sangria } \overline{12} \text { Iltros }\end{array}$ & $\begin{array}{l}300 \\
5,0 \text { grs. } \\
0,04 \\
330 \\
- \\
\end{array}$ \\
\hline $8 / 4 / 40$ & $\begin{array}{l}\text { Toxina } \\
\text { Acido ascórbico } \\
\text { Floculação. } \\
\text { Peso }\end{array}$ & $\begin{array}{l}350 \\
5,0 \text { grs. } \\
0,04 \\
340 \\
\end{array}$ & $\begin{array}{l}350 \\
5,0 \text { grs. } \\
0,08 \\
315\end{array}$ & $\begin{array}{l}\overline{-} \\
0,03 \\
315\end{array}$ & $\begin{array}{l}350 \\
5,0 \text { grs. } \\
0,04 \\
335\end{array}$ \\
\hline $16 / 4 / 40$ & $\begin{array}{l}\text { Toxina } \\
\text { Acido ascórbico } \\
\text { Floculação } \\
\text { Peso. }\end{array}$ & $\begin{array}{l}400 \\
5,0 \text { grs } \\
0,05 \\
340\end{array}$ & $\begin{array}{l}400 \\
5,0 \text { grs. } \\
0,08 \\
310\end{array}$ & $\begin{array}{l}- \\
\overline{-}\end{array}$ & $\begin{array}{l}400 \\
5,0 \text { grs. } \\
0,04 \\
325 \\
\end{array}$ \\
\hline $24 / 4 / 40$ & $\begin{array}{l}\text { Floculação : : : : } \\
\text { Peso : } \\
\text { Observações : }\end{array}$ & $\begin{array}{c}0,05 \\
335 \\
\text { Sangria } 12 \text { litros } \\
\end{array}$ & $\begin{array}{c}0,08 \\
\text { Sangria } 12 \text { litros }\end{array}$ & $\begin{array}{l}- \\
- \\
\end{array}$ & $\begin{array}{c}0,04 \\
\text { Sangria } 12 \\
\end{array}$ \\
\hline $14 / 5 / 40$ & $\begin{array}{l}\text { Toxina } \\
\text { Peso } .: \\
\end{array}$ & $\begin{array}{l}100 \\
345\end{array}$ & $\overline{-}$ & $\begin{array}{l}100 \\
345 \\
\end{array}$ & $\begin{array}{l}100 \\
325 \\
\end{array}$ \\
\hline $18 / 5 / 40$ & $\begin{array}{l}\text { Toxina } \\
\text { Peso }\end{array}$ & $\begin{array}{r}200 \\
350 \\
\end{array}$ & - & $\begin{array}{l}200 \\
350 \\
\end{array}$ & $\begin{array}{l}200 \\
325 \\
\end{array}$ \\
\hline $22 / 5 / 40$ & $\begin{array}{l}\text { Toxina } \\
\text { Floculação : : } \\
\text { Peso : }\end{array}$ & $\begin{array}{r}300 \\
0,12 \\
355 \\
\end{array}$ & $\begin{array}{r}300 \\
0,12 \\
300 \\
\end{array}$ & $\begin{array}{r}300 \\
0,06 \\
340 \\
\end{array}$ & $\begin{array}{r}300 \\
0,06 \\
325\end{array}$ \\
\hline $27 / 5 / 40$ & $\begin{array}{l}\text { Toxina } \\
\text { Floculação : : } \\
\text { Peso : }\end{array}$ & $\begin{array}{r}400 \\
0,05 \\
350\end{array}$ & $\begin{array}{r}400 \\
0,08 \\
300\end{array}$ & $\begin{array}{r}400 \\
0,03 \\
330\end{array}$ & $\begin{array}{r}400 \\
0,04 \\
334\end{array}$ \\
\hline
\end{tabular}

O segundo grupo (quadro n..$^{\circ}$ ), constituido de seis animais dos quais o de n.o 203 só foi injetado duas vêzes com doses de 2 grs. de ácido ascórbico, recebeu até 10 grs. de vitamina, sempre por via venosa. Esta última dose, aplicada por duas vêzes com intervalo de sete dias nos animais dêsse grupo, exceto para os de n.os 203 e 213, não apresentou resultados concordantes. E' assim que, permanecendo 
QUADRO N.o 5

Ação do ácido ascórbico na produção de aglutininas

\begin{tabular}{|c|c|c|c|c|c|c|c|}
\hline Data & & $\begin{array}{l}\text { Animal } \\
\text { n. } 0^{\circ} 203\end{array}$ & $\begin{array}{l}\text { Animal } \\
\mathrm{n}^{\circ} 204\end{array}$ & $\begin{array}{l}\text { Animal } \\
\text { n.0 205 }\end{array}$ & $\begin{array}{l}\text { Animal } \\
n .^{\circ} 207\end{array}$ & $\begin{array}{l}\text { Animal } \\
\mathrm{n} .^{\circ} 208\end{array}$ & $\begin{array}{l}\text { Animal } \\
\mathrm{n} 0^{\circ} 213\end{array}$ \\
\hline $23 / 3 / 40$ & $\begin{array}{l}\text { Toxina . : } \\
\text { Peso. }\end{array}$ & $\begin{array}{r}40 \\
300 \\
\end{array}$ & $\begin{array}{r}40 \\
300 \\
\end{array}$ & $\begin{array}{r}40 \\
296 \\
\end{array}$ & $\begin{array}{r}40 \\
360 \\
\end{array}$ & $\begin{array}{r}40 \\
295 \\
\end{array}$ & $\begin{array}{r}40 \\
365 \\
\end{array}$ \\
\hline $28 / 3 / 40$ & $\begin{array}{l}\text { Floculação : } \\
\text { Peso }\end{array}$ & $\overline{-}$ & $\begin{array}{r}0,2 \\
305 \\
\end{array}$ & $\begin{array}{r}0,2 \\
305 \\
\end{array}$ & $\begin{array}{r}0,05 \\
370 \\
\end{array}$ & $\overline{-}$ & $\begin{array}{r}0,12 \\
365 \\
\end{array}$ \\
\hline $29 / 3 / 40$ & $\begin{array}{l}\text { Toxina } \\
\text { Floculaçã̃o: } \\
\text { Peso : }\end{array}$ & $\begin{array}{r}60 \\
0,2 \\
300 \\
\end{array}$ & $\begin{array}{l}60 \\
- \\
\end{array}$ & $\begin{array}{l}- \\
-\end{array}$ & $\begin{array}{l}60 \\
- \\
-\end{array}$ & $\frac{60}{290}$ & $\begin{array}{l}60 \\
- \\
\end{array}$ \\
\hline $2 / 4 / 40$ & $\begin{array}{l}\text { Toxina } \\
\text { Ácido ascórbico } \\
\text { Floculaçăo } \\
\text { Peso. }\end{array}$ & \begin{tabular}{l|}
80 \\
2,0 grs. \\
$\mathbf{0 , 2}$ \\
300
\end{tabular} & $\begin{array}{c}80 \\
2,0 \text { grs. } \\
0,2 \\
300\end{array}$ & $\begin{array}{l}80 \\
2,0 \text { grs. } \\
0,05 \\
300\end{array}$ & $\begin{array}{c}\frac{80}{0,04} \\
365\end{array}$ & $\begin{array}{l}80 \\
2,0 \text { grs. } \\
0,15 \\
290\end{array}$ & $\begin{array}{r}80 \\
0,1 \\
365 \\
\end{array}$ \\
\hline $9 / 4 / 40$ & $\begin{array}{l}\text { Toxina } \\
\text { Ácido ascórbico } \\
\text { Floculação . } \\
\text { Peso }\end{array}$ & $\begin{array}{l}100 \\
2,0 \text { grs. } \\
0,2 \\
300\end{array}$ & $\begin{array}{l}100 \\
2,0 \text { grs. } \\
0,5 \\
300\end{array}$ & $\begin{array}{l}100 \\
2,0 \text { grs. } \\
0,05 \\
295\end{array}$ & $\begin{array}{l}100 \\
2,0 \text { grs. } \\
0,04 \\
360\end{array}$ & $\begin{array}{l}100 \\
2,0 \text { gis. } \\
0,15 \\
290\end{array}$ & $\begin{array}{l}100 \\
0,08 \\
363\end{array}$ \\
\hline $15 / 4 / 40$ & $\begin{array}{l}\text { Toxina } \\
\text { Ácido ascórbico } \\
\text { Floculação } \\
\text { Peso. }\end{array}$ & $\overline{\bar{z}}$ & $\begin{array}{l}130 \\
5,0 \mathrm{grs} \\
0,15 \\
295\end{array}$ & $\begin{array}{l}130 \\
5,0 \text { grs. } \\
0,05 \\
290\end{array}$ & $\begin{array}{l}130 \\
5,0 \text { grs. } \\
0,04 \\
-\end{array}$ & $\begin{array}{l}130 \\
5,0 \text { grs. } \\
0,15 \\
295\end{array}$ & $\begin{array}{l}130 \\
\overline{0,08} \\
365\end{array}$ \\
\hline $17 / 4 / 40$ & Observações . & $\begin{array}{l}\text { Sangria } \\
6 \text { litros } \\
\end{array}$ & - & - & - & - & - \\
\hline $22 / 4 / 40$ & $\begin{array}{l}\text { Toxina . } \\
\text { Ácido ascórbico } \\
\text { Floculação } \\
\text { Peso. } \\
\text { Observações }\end{array}$ & $\left|\begin{array}{c}- \\
- \\
- \\
- \\
\text { Passou para } \\
\text { o tetano }\end{array}\right|$ & $\begin{array}{c}170 \\
10,0 \text { grs. } \\
0,15 \\
290 \\
-\end{array}$ & $\begin{array}{c}170 \\
10,0 \text { grs. } \\
0,04 \\
290 \\
-\end{array}$ & $\begin{array}{c}170 \\
10,0 \text { grs. } \\
0,04 \\
-- \\
-\end{array}$ & $\begin{array}{c}170 \\
10,0 \text { grs. } \\
0,15 \\
290 \\
-\end{array}$ & $\begin{array}{c}170 \\
10,0 \text { grs. } \\
0,08 \\
368 \\
- \\
\end{array}$ \\
\hline $29 / 4 / 40$ & $\begin{array}{l}\text { Toxina } \\
\text { Ácido ascórbico } \\
\text { Floculação } \\
\text { Peso }\end{array}$ & $\begin{array}{l}- \\
=\end{array}$ & $\begin{array}{c}200 \\
10,0 \text { grs. } \\
0,12 \\
295\end{array}$ & $\begin{array}{c}200 \\
10,0 \text { grs. } \\
0,04 \\
290\end{array}$ & $\begin{array}{c}200 \\
10,0 \text { grs. } \\
0,04 \\
360\end{array}$ & $\begin{array}{c}200 \\
10,0 \text { grs. } \\
0,15 \\
300\end{array}$ & $\begin{array}{l}200 \\
\overline{0,08} \\
370\end{array}$ \\
\hline $6 / 5 / 40$ & $\begin{array}{l}\text { Floculação } \\
\text { Peso } \\
\text { Observações }\end{array}$ & $\begin{array}{l}- \\
-\end{array}$ & $\underset{\substack{\text { Sangria } \\
6 \text { litros }}}{0,12}$ & \begin{tabular}{c}
0,03 \\
\hdashline- \\
Sangria \\
12 litros
\end{tabular} & $\begin{array}{c}0,05 \\
350 \\
\text { Sangria } \\
12 \text { litros }\end{array}$ & $\frac{0,15}{\substack{\text { Sangria } \\
6 \text { litros }}}$ & $\begin{array}{c}0,08 \\
\begin{array}{c}\text { Sangria } \\
12 \text { litros }\end{array}\end{array}$ \\
\hline
\end{tabular}

inalterado o valor da floculação para o sôro de um dos animais, o de n. ${ }^{\circ}$ 208, registrou-se entretanto ligeiro aumento dêsse valor para os outros animais dêsse grupo. Verificámos que esse teor, mais alto em aglutininas, não correu por conta da injeção da vitamina pois, como se nota para o animal n. ${ }^{\circ}$ 207, o sôro apresentou poder antitóxico mais elevado antes de ser injetado com ácido ascórbico, permanecendo, nessas condições, até o fim da observação. 
QUADRO N.06

Ação do ácido ascórbico na produção de aglutininas

\begin{tabular}{|c|c|c|c|c|c|c|c|c|c|c|c|c|}
\hline Data & & & $\begin{array}{c}\text { Animal } \\
\text { n. }{ }^{\circ} 209\end{array}$ & $\begin{array}{l}\text { Animal } \\
\mathrm{n} \cdot{ }^{0} 210\end{array}$ & $\begin{array}{l}\text { Animal } \\
\mathrm{n} .0211\end{array}$ & $\begin{array}{l}\text { Animal } \\
\mathrm{n}, 0^{0} 218\end{array}$ & $\begin{array}{l}\text { Animal } \\
\mathrm{n} 0^{\circ} 212\end{array}$ & $\begin{array}{l}\text { Animal } \\
\mathrm{n} .0^{\circ} 214\end{array}$ & $\begin{array}{l}\text { Animal } \\
\mathrm{n} .0216\end{array}$ & $\begin{array}{l}\text { Animal } \\
\text { n. }{ }^{\circ} 217\end{array}$ & $\begin{array}{l}\text { Animal } \\
\mathrm{n} 0^{0} 219\end{array}$ & $\begin{array}{c}\text { Animal } \\
\mathrm{n} .0220\end{array}$ \\
\hline $23 / 3 / 40$ & $\begin{array}{l}\text { Toxina . } \\
\text { Peso. }\end{array}$ & . & $\begin{array}{c}40 \\
330\end{array}$ & $\begin{array}{c}40 \\
400\end{array}$ & $\begin{array}{c}40 \\
370\end{array}$ & $\begin{array}{c}40 \\
390\end{array}$ & $\begin{array}{c}40 \\
310\end{array}$ & $\begin{array}{c}40 \\
325\end{array}$ & $\begin{array}{c}40 \\
395\end{array}$ & $\begin{array}{c}40 \\
330\end{array}$ & $\begin{array}{c}40 \\
350\end{array}$ & $\begin{array}{c}40 \\
320\end{array}$ \\
\hline $28 / 3 / 40$ & $\begin{array}{l}\text { Floculação . } \\
\text { Peso . }\end{array}$ & . & $\begin{array}{r}0,2 \\
340\end{array}$ & $\begin{array}{r}0,2 \\
405\end{array}$ & $\begin{array}{r}0,2 \\
375 \\
\end{array}$ & $\begin{array}{l}0,12 \\
396\end{array}$ & $\begin{array}{r}0,1 \\
325 \\
\end{array}$ & $\begin{array}{r}0,2 \\
320 \\
\end{array}$ & $\begin{array}{l}0,08 \\
395\end{array}$ & $\begin{array}{l}0,12 \\
332\end{array}$ & $\begin{array}{l}0,06 \\
370\end{array}$ & $\begin{array}{r}0,2 \\
320\end{array}$ \\
\hline $29 / 3 / 40$ & Toxina. & . . & 60 & 60 & 60 & 60 & 60 & 60 & 60 & 60 & 60 & 60 \\
\hline $2 / 4 / 40$ & $\begin{array}{l}\text { Toxina } \\
\text { Floculação: } \\
\text { Peso . }\end{array}$ & $\begin{array}{l}. \\
: \\
.\end{array}$ & $\begin{array}{c}80 \\
0,2 \\
345 \\
\end{array}$ & $\begin{array}{l}80 \\
0,15 \\
400 \\
\end{array}$ & $\begin{array}{l}80 \\
0,15 \\
363 \\
\end{array}$ & $\begin{array}{c}80 \\
0,1 \\
390 \\
\end{array}$ & $\begin{array}{c}80 \\
0,1 \\
312 \\
\end{array}$ & $\begin{array}{l}80 \\
0,12 \\
323 \\
\end{array}$ & $\begin{array}{l}80 \\
0,06 \\
395 \\
\end{array}$ & $\begin{array}{l}80 \\
0,08 \\
320 \\
\end{array}$ & $\begin{array}{l}80 \\
0,05 \\
360 \\
\end{array}$ & $\begin{array}{c}80 \\
0,2 \\
310 \\
\end{array}$ \\
\hline $9 / 4 / 40$ & $\begin{array}{l}\text { Toxina } \\
\text { Floculação: } \\
\text { Peso. }\end{array}$ & $\dot{:}:$ & $\begin{array}{l}100 \\
0,15 \\
345 \\
\end{array}$ & $\begin{array}{l}100 \\
0,12 \\
400 \\
\end{array}$ & $\begin{array}{l}100 \\
0,12 \\
370 \\
\end{array}$ & $\begin{array}{r}100 \\
0,1 \\
385 \\
\end{array}$ & $\begin{array}{l}100 \\
0,12 \\
315 \\
\end{array}$ & $\begin{array}{r}100 \\
0,1 \\
325 \\
\end{array}$ & $\begin{array}{l}100 \\
0,06 \\
390 \\
\end{array}$ & $\begin{array}{l}100 \\
0,06 \\
320 \\
\end{array}$ & $\begin{array}{l}100 \\
0,05 \\
350 \\
\end{array}$ & $\begin{array}{l}100 \\
0,15 \\
305 \\
\end{array}$ \\
\hline $15 / 4 / 40$ & $\begin{array}{l}\text { Toxina } \\
\text { Floculação: } \\
\text { Peso : } \\
\text { Observações }\end{array}$ & 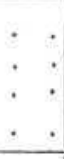 & \begin{tabular}{|c|}
130 \\
0,12 \\
335 \\
Passou para \\
o tetano \\
\end{tabular} & \begin{tabular}{|c|}
130 \\
0,12 \\
390 \\
Passou para \\
o tetano \\
\end{tabular} & \begin{tabular}{c|}
130 \\
0,12 \\
355 \\
Passou para \\
o tetano \\
\end{tabular} & $\begin{array}{c}130 \\
0,1 \\
385 \\
\text { Passou para } \\
\text { o tetano } \\
\end{array}$ & \begin{tabular}{|c|}
130 \\
0,12 \\
300 \\
Passou para \\
o tetano \\
\end{tabular} & $\begin{array}{r}130 \\
0,1 \\
315 \\
- \\
\end{array}$ & $\begin{array}{c}130 \\
0,06 \\
390 \\
- \\
\end{array}$ & $\begin{array}{l}130 \\
0,06 \\
320 \\
- \\
\end{array}$ & $\begin{array}{l}130 \\
0,06 \\
355 \\
- \\
\end{array}$ & $\begin{array}{c}130 \\
0,15 \\
300 \\
- \\
\end{array}$ \\
\hline $22 / 4 / 40$ & $\begin{array}{l}\text { Toxina : } \\
\text { Floculação : } \\
\text { Peso . }\end{array}$ & $\dot{5}:$ & & & & & & $\begin{array}{l}170 \\
0,12 \\
310 \\
\end{array}$ & $\begin{array}{l}170 \\
0,06 \\
380 \\
\end{array}$ & $\begin{array}{l}170 \\
0,06 \\
310 \\
\end{array}$ & $\begin{array}{l}170 \\
0,06 \\
345 \\
\end{array}$ & $\begin{array}{l}170 \\
0,15 \\
290 \\
\end{array}$ \\
\hline $29 / 4 / 40$ & $\begin{array}{l}\text { Toxina } \\
\text { Floculação: } \\
\text { Peso . }\end{array}$ & $\dot{5}:$ & & & & & & $\begin{array}{r}200 \\
0,1 \\
310 \\
\end{array}$ & $\begin{array}{l}200 \\
0,06 \\
390 \\
\end{array}$ & $\begin{array}{l}200 \\
0,06 \\
320\end{array}$ & $\begin{array}{l}200 \\
0,06 \\
350 \\
\end{array}$ & $\begin{array}{l}200 \\
0,15 \\
300\end{array}$ \\
\hline $6 / 5 / 40$ & $\begin{array}{l}\text { Floculação . } \\
\text { Observações }\end{array}$ & $\begin{array}{l}. \\
. \\
.\end{array}$ & & & & & & $\begin{array}{c}0,12 \\
\text { Sangria } 6 \\
\text { litros } \\
\text { Passou para } \\
\text { o tetano } \\
\end{array}$ & $\begin{array}{c}0,06 \\
\begin{array}{c}\text { Sangria } 12 \\
\text { litros }\end{array}\end{array}$ & $\begin{array}{c}0,06 \\
\begin{array}{c}\text { Sangria } 12 \\
\text { litros }\end{array}\end{array}$ & $\begin{array}{c}0,06 \\
\begin{array}{c}\text { Sangria } 12 \\
\text { litros }\end{array}\end{array}$ & - \\
\hline
\end{tabular}


Reproduzimos no quadro n. 6 a imunização procedida com o grupo de animais testemunhos e o respectivo título de. floculação de seus sôros facilitando êsses dados, tomados como têrmo de comparação, a interpretação dos resultados obtidos com os animais submetidos ao tratamento com ácido ascórbico. Podemos, dêsse modo, verificar que o poder antitóxico do sôro dos animais injetados com vitamina $C$ não foi influenciado favoravelmente pela mesma, chegando, pelo contrário, em um caso, (animal n. ${ }^{\circ}$ 69) a ser fracamente prejudicado quando se comparam os resultados oferecidos pelos animais dos grupos vitaminizados e do grupo testemunho.

- Cabe-nos externar os nossos agradecimentos ao Prof. Fonseca Ribeiro pela orientação e auxílio prestados na elaboração dêste trabalho.

\section{CONCLUSÕES}

Do que foi exposto é lícito concluir:

1) O ácido ascórbico tem notável ação estimulante sôbre a produção de precipitinas, quando injetado por via venosa.

2) Não são necessárias, para que tal ação se verifique, injeções repetidas da vitamina juntamente com o antígeno (MADISON e col.), nem tão pouco tratamento vitamínico intensivo imediatamente antes da imunização (JUSATz). Uma injeção apenas de ácido ascórbico, imediatamente depois de terminada a imunização, é suficiente para conferir alto título precipitante ao sôro.

3) Tendo em vista a facilidade de obtenção de sôros altamente precipitantes, o teste biológico pode, vantajosamente, se alinhar entre as provas de rotina dos laboratórios especializados e daqueles anexos aos estabelecimentos onde se elaboram produtos de salsicharia, vindo em auxílio do técnico encarregado de caraterizar carnes dos vários animais.

4) Nessas condições, o teste biológico oferecendo toda a segurança e precisão de estrita especificidade deve, na pesquisa de fraudes por substituição, ser preferido a tôdas as provas de laboratório atualmente empregadas.

5) Empregando doses mais fracas de ácido ascórbico do que os autores citados (Madison e col., Montalti e Passerini), servindonos de cavalos como animais de experiência, não conseguimos resultados satisfatórios na produção de aglutininas, quando a vitamina $C$ é injetada por via venosa. 


\section{PRECIPITIN TEST IN MEAT INSPECTION \\ ACTION OF ASCORBIC ACID ON THE PREPARATION OF HIGH TITLE SERUMS}

From the above we may conclude:

1) Ascorbic Acid has remarkable stimulating action on the production of precipitins when injected into the vein.

2) The repeated injection of vitamin with antigen (Madison and co-workers) is not necessary for that action to take place, nor is necessary the intensive treatment with the vitamin before the immunization (JuSATZ). A singe injection of Ascorbic Acid, immediatelly after immunization, is sufficient to give the serum high precipitating title.

3) Having in view the facility in obtaining highly precipiting serums, the biological test may, advantageously, be included with the routine tests in specialised laboratories, and those of establishments where sausages are manufactured, becoming a help to the expert employed in charaterizing the flesh of various animals.

4) In such conditions the biological test, offering entire sureness and strict precision in specificity, should be preferred to all laboratory tests presently employed in the investigation of fraud by substitution.

5) Employing weaker doses of Ascorbic Acid than those prescribed by the mentioned authors (Madison and co-workers, Montalti and Passerini) and using horses as experimental animals, we have not obtained satisfactory results in the production of aglutinins, when vitamin $C$ is injected into the vein.

\section{BIBLIOGRAFIA}

1) - Piettre, M. - Inspection des viandes et des aliments d'origine carnée. Industrie et législation. Viande saine. Paris, J. B. Baillière et fils, 1921.

2) - Ministerio da Agricultura - Departamento Nacional da Produção ANIMAL - Regulamento da Inspeção federal de carnes e derivados. 2. ${ }^{a}$ ed. Rio de Janeiro, Diretoria de Estatística da Produção, 1935.

3) - Bertolini, G. - Cazzella A. - Ispezione delle carni. Igiene generale. Torino, Unione tipografico editrice torinese, 1928.

4) - Edelmann, R. - Text-book of meat hygiene. 6th. ed. London, J. \& A. Churchill, 1933.

5) - Farreras - Sanz Egaña - La inspección veterinaria en los mataderos, mercados y vaquerias. 3.a ed. Barcelona, Revista Veterinaria de España, 1935.

6) - Ostertac, R. V. - Text-book of meat inspection. London, Baillière, Tindal \& Cox, 1934.

7) - Ribeiro, D. Fonseca - Alguns aspectos da teoria físico-química da imunidade. In Memorial apresentado para o concurso ao cargo de professor catedrático de Química orgânica e biológica na Fac. Med. Vet. São Paulo. 1936. 
8) - Jusatz, H. J. - Der Einfluss der Vitamine auf den Immunitätszustand des tierischen Organismus I. Die fettlöslichen Vitamine A und D. II. Wasserlösliche Vitamine. Zeitschr. Immun, forsch. 88: 472/83, 1936. Ref. Bull. Inst. Pasteur, 35 (1): 32/3, 1937.

9) - Madison, R. R. - MANwarino, W. H. - Ascorbic acid stimulation of specific antibody production. Proc. Soc. Exp. Biol. Med. 37, 402. Ref. Bull. Inst. Pasteur 37 (4): 232, 1939.

10) - Madison, R. R. - Fish M. - FRICK O. - Vitamin C inhibition of agglutinin production. Proc. Soc. Exp. Biol. Med. 39, 54/7, 1938. Ref. Chemical Abstracts 33 (18): 7385.

11) - Montalti, M. - Passerini P. - Influence of ascorbic acid on the production of anti-typhoid agglutinins. Boll. Ist. Sieroterap. Milan. 17, 495/ 503, 1938. Ref. Chemical Abstracts 33 (9): 3428.

12) - Cattaneo, C. - Morellini, M. - Action of sodium hyposulfite, ascorbic acid and adrenaline on the experimental production of agglutinins. Boll. Ist. Sieroterap Milan. 18, 52/6, 1939. Ref. Chemical Abstracts 33 (9) : 3446. 